\title{
Perancangan dan Pengukuran Kinerja Program Inisiatif Perspektif Proses Bisnis Internal
}

\author{
Qurtubi $^{1}$
}

\begin{abstract}
This paper discusses the design and performance measurement initiative internal business process perspective balanced scorecard, a case study at CV. Fateha Compunet, a company engaged in the trade of computers and official equipments. Research carried out by identifying a problem with the method of observation, formulating business process problems that lead to complaints, collecting primary data and secondary data such as key performance indicators and other supporting data. Survey methods used in the study is the importance analysis. In this technique, the respondents were asked to rank various attributes of a sub program initiative is based on the degree of importance of each of these attributes. The results showed that based on the monitoring and evaluation of programs key performance indicator value initiatives classified as well so that the target company would potentially be achieved.
\end{abstract}

Keywords. balanced scorecard, key performance indicator, performance measurement, initiative program, business process.

\begin{abstract}
Abstrak. Artikel ini membahas tentang perancangan dan pengukuran kinerja program inisiatif perspektif proses bisnis internal balanced scorecard, studi kasus di CV. Fateha Compunet, sebuah perusahaan yang bergerak di bidang perdagangan komputer dan mesin kantor. Penelitian dilakukan dengan mengidentifikasi masalah dengan metode observasi, merumuskan masalah proses bisnis yang menimbulkan keluhan, mengumpulkan data primer dan data skunder seperti key performance indicator serta data-data pendukung lainnya. Metode survei yang digunakan dalam penelitian adalah importance analysis. Dalam teknik ini, responden diminta untuk meranking berbagai atribut dari sub program inisiatif berdasarkan derajat pentingnya setiap atribut tersebut. Hasil penelitian menunjukkan bahwa berdasarkan monitoring dan evaluasi program-program inisiatif nilai key performance indicator berklasifikasi baik sehingga target perusahaan berpotensi akan tercapai.
\end{abstract}

Kata kunci. balanced scorecard, key performance indicator, pengukuran kinerja, program inisiatif, proses bisnis.

\section{PENDAhUluan}

CV. Fateha Compunet merupakan perusahaan bisnis yang bergerak di bidang perdagangan komputer dan mesin kantor. Perkembangan bisnis CV. Fateha Compunet tidak ditunjang dengan penataan proses bisnis yang baik sehingga menimbulkan banyak keluhan dari customer (pelanggan) dan dari internal karyawan sebagai stakeholder perusahaan. Keluhan dari pelanggan misalnya proses bisnis yang lambat, sedangkan dari karyawan antara lain mengeluhkan tidak

\footnotetext{
${ }^{1}$ Qurtubi, Program Studi Teknik Industri Universitas Islam Indonesia, Jl. Kaliurang Km.14,5 Telp (0274) 895287

Sleman Yogyakarta 55584 (email: qurtubi@uii.ac.id)
}

Diajukan: 26-05-2016 Disetujui: 25-05-2016 adanya job description (deskripsi kerja) dan standart operating procedure (SOP) yang jelas mengakibatkan terjadinya banyak kesalahan yang dilakukan karyawan.

Keluhan di atas mengindikasikan adanya permasalahan pada proses bisnis perusahaan. Padahal proses bisnis adalah hal yang sangat penting dalam kehidupan perusahaan. Oleh karena itu perlu dilakukan perancangan dan pengukuran kinerja program insiatif perspektif proses bisnis internal.

\section{Balanced scorecard}

Balanced scorecard merupakan suatu sistem manajemen, pengukuran, dan pengendalian yang secara cepat, tepat, dan komprehensif dapat memberikan pemahaman kepada manajer tentang performance bisnis. Pengukuran kinerja tersebut memandang unit bisnis dari empat perspektif, 
yaitu perspektif keuangan, pelanggan, proses bisnis dalam perusahaan, serta proses pembelajaran dan pertumbuhan. Melalui mekanisme sebab akibat (cause and effect), perspektif keuangan menjadi tolak ukur utama yang dijelaskan oleh tolak ukur operasional pada tiga perspektif lainnya sebagai driver (lead indicator) (Yuwono, dkk., 2003).

\section{Proses bisnis}

Proses adalah seperangkat kegiatan yang saling berkaitan yang membutuhkan masukan dan mentransformasikannya untuk menghasilkan suatu keluaran. Idealnya, transformasi yang terjadi dalam proses memberi nilai tambah bagi masukan dan menghasilkan keluaran yang lebih berguna dan efektif bagi penerimanya baik di sisi hulu ataupun hilir (Johansson, dkk., 1995).

Proses bisnis adalah suatu organisasi yang terdiri dari manusia, material, energi, peralatan, dan prosedur pada rancangan aktivitas kerja untuk menghasilkan hasil akhir spesifik. Ada dua karakteristik penting dari suatu proses bisnis, yaitu: adanya pelanggan, terjadi batasan organisasi dan terlepas dari suatu seri dan aktivitas yang saling terkait yang menggunakan sumber daya dari organisasi untuk menghasilkan suatu hasil yang dapat diukur, baik produk maupun jasa (Davenport \& Short, 1995).

\section{Teknologi informasi dan kinerja}

Peppard \& Rowland (1995) mengatakan, terdapat empat hal yang dapat dilakukan oleh teknologi informasi dalam meningkatkan kinerja perusahaan melalui perubahan pada karakteristik proses yaitu menghilangkan proses (process elimination), menyederhanakan proses (process simplication), menyatukan proses (process integration) dan melakukan otomisasi (process automation).

\section{Penetapan target}

Menurut Kaplan (2006), penetapan target adalah pusat implementasi yang efektif dari balanced scorecard berdasarkan manajemen strategi. Perusahaan dapat juga mengatur target internal untuk meningkatkan proses kinerja.

\section{Indikator kinerja}

Indikator kinerja atau performance indicator adalah penilaian terhadap hasil kerja pelaksanaan program inisiatif yang telah ditetapkan perusahaan. Penilaian diperoleh berdasarkan hasil monitoring dan evaluasi pelaksanaan program dan aktivitas inisiattif perusahaan. Hasil penilaian ini merupakan petunjuk, apakah target perusahaan akan dapat atau tidak dapat dicapai pada saatnya. Makin tinggi hasil penilaian atau indikator kinerja, akan makin baik dan akan makin besar kemungkinannya perusahaan akan mencapai target perusahaan pada waktu yang telah ditentukan (Thaib, 2012).

\section{Indikator kinerja utama}

Indikator kinerja utama atau key performance indicator adalah penilaian terhadap hasil kerja pelaksanaan program-program inisiatif utama yang telah ditetapkan perusahaan, pada setiap perspektif perusahaan yaitu pemegang saham, pelanggan, internal proses dan pertumbuhan pembelajaran. Klasifikasi indikator kinerja utama program inisiatif dan target perusahaan ditunjukkan pada Tabel 1 (Thaib, 2012).

\section{Metodologi}

Metode yang digunakan
mengidentifikasi masalah adalah metode
observasi, melakukan perumusan masalah
mengenai proses bisnis di perusahaan yang
menimbulkan keluhan.
mengumpulkan data baik data primer yang

Tabel 1.Nilai key performance indicator program inisiatif

\begin{tabular}{|c|c|}
\hline \multicolumn{2}{|r|}{ Nilai KPI program inisiatif adalah $1,00-4,00$} \\
\hline $3,50<X \leq 4,00$ & $\begin{array}{l}\text { Menunjukkan nilai KPI berklasifikasi sangat baik, target } \\
\text { perusahaan berpotensi pasti tercapai }\end{array}$ \\
\hline $3,00<X \leq 3,50$ & $\begin{array}{l}\text { Menunjukkan nilai KPI berklasifikasi baik, target perusahaan } \\
\text { berpotensi akan tercapai }\end{array}$ \\
\hline $2,50<X \leq 3,00$ & $\begin{array}{l}\text { Menunjukkan nilai KPI berklasifikasi kurang, target perusahaan } \\
\text { berpotensi tidak akan tercapai }\end{array}$ \\
\hline$X \leq 2,50$ & $\begin{array}{l}\text { Menunjukkan nilai KPI berklasifikasi sangat kurang, target } \\
\text { perusahaan berpotensi sulit dicapai }\end{array}$ \\
\hline
\end{tabular}


didapatkan melalui observasi dan brainstorming maupun data skunder seperti key performance indicator, serta data-data pendukung lainnya.

\section{HASIL DAN PEMBAHASAN}

Dari berbagai data yang ada seperti data perencanaan strategis, target-target strategis, dan tolak ukur telah dibuat rancangan balanced scorecard CV. Fateha Compunet seperti pada Tabel 2.

\section{Keluhan pelanggan dan karyawan}

Keluhan-keluhan stakeholder yang menjadi dasar permasalahan dalam penelitian dapat dilihat dalam Tabel 3.

\section{Identifikasi masalah dan penyebabnya}

Hasil identifikasi masalah dan penyebab masalah dicantumkan dalam Tabel 4.

\section{Perancangan dan perencanaan program inisiatif}

Program inisiatif merupakan program kerja yang memberikan dampak strategis pada perusahaan di luar program kerja rutin atau harian yang bersifat reguler. Program inisiatif sangat menentukan pencapaian target kinerja perusahaan

Tabel 2. Balanced scorecard CV. Fateha Compunet

\begin{tabular}{|c|c|c|}
\hline \multirow[b]{2}{*}{ Target Strategis } & \multicolumn{2}{|c|}{ Ukuran Strategis } \\
\hline & $\begin{array}{c}\text { Core Outcomes/ Lag } \\
\text { Indicator } \\
\text { (Indikator Akibat) }\end{array}$ & $\begin{array}{c}\text { Performance Driver/ } \\
\text { Lead Indicator } \\
\text { (Indikator Sebab) }\end{array}$ \\
\hline $\begin{array}{l}\text { Perspektif keuangan } \\
\text { - Meningkatkan pendapatan }\end{array}$ & Net Margin dan ROI & Bauran pendapatan \\
\hline $\begin{array}{l}\text { Perspektif pelanggan } \\
\text { - Meningkatkan hubungan pelanggan. } \\
\text { - Meningkatkan kualitas pelayanan. } \\
\text { - Menambah toko baru. }\end{array}$ & $\begin{array}{l}\text { Kepuasan pelanggan } \\
\text { Market share. }\end{array}$ & $\begin{array}{l}\text { Survei kepuasan } \\
\text { pelanggan. } \\
\text { Customer acquisition \& } \\
\text { customer retention. }\end{array}$ \\
\hline $\begin{array}{l}\text { Perspektif proses bisnis internal } \\
\text { - Mengembangkan customize product/service } \\
\text { - Meningkatkan pemanfaatan teknologi } \\
\text { informasi } \\
\text { - Mengembangkan proses bisnis responsif } \\
\text { efisien }\end{array}$ & $\begin{array}{l}\text { Pendapatan customize } \\
\text { product } \\
\text { Tingkat kesalahan } \\
\text { pelayanan. } \\
\text { Waktu proses. }\end{array}$ & $\begin{array}{l}\text { Inovasi produk/jasa } \\
\text { service } \\
\text { Service Quality Audit. } \\
\text { Rekayasa ulang proses } \\
\text { bisnis }\end{array}$ \\
\hline $\begin{array}{l}\text { Perspektif pertumbuhan dan pembelajaran } \\
\text { - Meningkatkan kemampuan karyawan. }\end{array}$ & Kepuasan karyawan. & $\begin{array}{l}\text { Survei kepuasan } \\
\text { pelanggan }\end{array}$ \\
\hline
\end{tabular}

(Sumber: Qurtubi, 2013)

Tabel 3. Keluhan-keluhan stakeholder

\begin{tabular}{|c|c|c|c|}
\hline No. & Stakeholder & Status & Keluhan \\
\hline 1 & Stakeholder 1 & Karyawan & Tidak ada job description (dekskripsi kerja) yang jelas. \\
\hline 2 & Stakeholder 2 & Karyawan & Tidak ada standart operating procedure (SOP) yang baku. \\
\hline 3 & Stakeholder 3 & Karyawan & Tidak ada job training untuk karyawan baru. \\
\hline 4 & Stakeholder 4 & Karyawan & Layanan manual, belum terkomputerisasi. \\
\hline 5 & Stakeholder 5 & Karyawan & Tumpang tindih pekerjaan, perintah kerja tidak jelas. \\
\hline 6 & Stakeholder 6 & Pelanggan & $\begin{array}{l}\text { Proses perbaikan lama, harus menunggu komponen } \\
\text { datang. }\end{array}$ \\
\hline 7 & Stakeholder 7 & Pelanggan & Arsip nota pembelian tidak ada (sulit ditemukan). \\
\hline 8 & Stakeholder 8 & Pelanggan & Delivery service tidak konsisten, tergantung waktu kosong \\
\hline 9 & Stakeholder 9 & Pelanggan & $\begin{array}{l}\text { Perkiraan biaya dan waktu perbaikan tidak bisa langsung } \\
\text { disampaikan }\end{array}$ \\
\hline 10 & Stakeholder 10 & Pelanggan & Tidak ada layanan perbaikan langsung di tempat pelanggan \\
\hline
\end{tabular}


Tabel 4. Identifikasi masalah dan penyebab masalah

\begin{tabular}{lllll}
\hline \multirow{2}{*}{$\begin{array}{l}\text { No } \\
\text { masalah }\end{array}$} & \multicolumn{2}{l}{ Identifikasi penyebab masalah } & Bagian \\
\hline 1 & $\begin{array}{l}\text { Waktu proses } \\
\text { lama }\end{array}$ & a. & Pekerjaan menumpuk karena belum memakai skala prioritas. & Service \\
\cline { 2 - 5 } & b. & Sulit mencari arsip karena penomoran kacau. & Administrasi \\
\hline 2 & $\begin{array}{l}\text { Banyak } \\
\text { kesalahan }\end{array}$ & a. & Karyawan kurang menguasai karena tidak ada training kerja. & Service \\
\hline b. & Tumpang tindih pekerjaan karena job description tidak jelas. & Administrasi \\
\hline 3 & Idle time & a. & $\begin{array}{l}\text { Menunggu konfirmasi pelanggan karena biaya sulit } \\
\text { diperkirakan. }\end{array}$ & Administrasi \\
& & b. & Pemesanan komponen keluar kota karena stok tidak lengkap. & Service \\
\hline 4 & Sistem buruk & a. & Belum komputerisasi karena belum ada program yang sesuai. & Administrasi \\
\cline { 2 - 5 } & b. & Desain sistem buruk karena belum ada SOP yang baku. & Administrasi \\
\hline (Sumber: Qurtubi, 2013) & &
\end{tabular}

Tabel 5. Program inisiatif perspektif proses bisnis internal

\begin{tabular}{|c|c|c|}
\hline \multicolumn{3}{|c|}{ Tujuan Strategik } \\
\hline Target & \multicolumn{2}{|c|}{$\begin{array}{l}\text { 1. Menghasilkan customize product / service dengan cepat dan murah } \\
\text { 2. Meningkatkan pemanfaatan teknologi informasi } \\
\text { 3. Mengembangkan proses operasi yang responsif dan efisien }\end{array}$} \\
\hline \multirow{9}{*}{$\begin{array}{l}\text { Program } \\
\text { Inisiatif }\end{array}$} & \multirow[b]{2}{*}{ Sub Program 1} & Menambah jenis produk yang ditawarkan \\
\hline & & Menciptakan jenis layanan baru yang bernilai tambah \\
\hline & \multirow{3}{*}{ Sub Program 2} & Merancang sistem informasi penjualan \\
\hline & & Membuat sistem informasi penjualan \\
\hline & & Mengaplikasikan sistem informasi penjualan \\
\hline & \multirow{4}{*}{ Sub Program 3} & Rekayasa ulang proses pengantaran komputer \\
\hline & & Rekasaya ulang proses penanganan garansi \\
\hline & & Rekayasa ulang proses perbaikan komputer \\
\hline & & Rekayasa ulang proses pembayaran \\
\hline
\end{tabular}

jangka panjang. Program inisiatif CV. Fateha Compunet ditunjukkan pada Tabel 5.

Dari program-program inisiatif di atas, dilakukan survei pada karyawan dan pelanggan dalam bentuk kuesioner dengan pendekatan multi atribut importance analysis. Dari hasil survei dilakukan perhitungan skor untuk menentukan prioritas program inisiatif yang akan dijalankan.

\section{Survei importance analysis}

Survei dilakukan dengan mengajukan pertanyaan sebagai berikut:

Kami menyusun kuesioner ini dalam upaya membantu perusahaan agar mendapatkan pemahaman yang lebih jelas tentang program inisiatif apa yang anda inginkan dan harapkan dari proses bisnis internal perusahaan. Silakan beri urutan kepentingan pada hal-hal berikut ini. Ranking 1 menyatakan atribut paling penting.

Daftar pertanyaan survei dapat dilihat dalam Tabel 6. Hasil perhitungan skor sub program-sub program inisiatif dan kriteria interpretasi skor dapat dilihat pada Tabel 7.

\section{Uji validitas}

Para responden dianggap sebagai populasi. Rumus standar deviasi untuk populasi ditampilkan pada Pers. (1).

$S_{\text {dev }}=\sqrt{\frac{\left(x_{i}-x\right)}{N}}$

Keterangan:

$x=$ skor rata-rata

$x_{i}=$ skor variabel ke-i

$N=$ jumlah responden (populasi)

Standar deviasi dilakukan untuk menguji kesepakatan atau kesamaan pendapat di antara para responden mengenai topik yang ditanyakan. Standar deviasi semua komponen berada di bawah 0,5 yakni 0,076, berarti terdapat kesamaan pendapat di antara ke-10 responden, sehingga data dianggap sah. Jawaban dianggap sah kalau perbedaannya sedikit, yaitu jika standar deviasi 0,5 atau lebih rendah. Kalau standar deviasi di atas 0,5 maka data dianggap tidak sah. Dengan demikian dapat disimpulkan valid dengan angka 
Tabel 6. Pertanyaan survei importance analysis

\begin{tabular}{|c|c|c|c|c|c|}
\hline Atribut & \multicolumn{5}{|c|}{ Tingkat Kepentingan } \\
\hline Menambah jenis produk yang ditawarkan & 1 & 2 & 3 & 4 & 5 \\
\hline Menciptakan jenis layanan baru yang bernilai tambah & 1 & 2 & 3 & 4 & 5 \\
\hline Merancang sistem informasi penjualan & 1 & 2 & 3 & 4 & 5 \\
\hline Membuat sistem informasi penjualan & 1 & 2 & 3 & 4 & 5 \\
\hline Mengaplikasikan sistem informasi penjualan & 1 & 2 & 3 & 4 & 5 \\
\hline Merekayasa ulang proses bisnis perbaikan komputer & 1 & 2 & 3 & 4 & 5 \\
\hline Merekayasa ulang proses bisnis penanganan garansi & 1 & 2 & 3 & 4 & 5 \\
\hline Merekayasa ulang proses bisnis pengantaran barang & 1 & 2 & 3 & 4 & 5 \\
\hline Merekayasa ulang proses bisnis pembayaran & 1 & 2 & 3 & 4 & 5 \\
\hline Skor: & \multicolumn{4}{|c|}{ Kriteria interpretasi skor: } & \\
\hline Skor $5=$ sangat penting & $0 \%$ & & \multicolumn{3}{|c|}{$=$ sangat lemah } \\
\hline Skor $4=$ penting & $21 \%$ & & \multicolumn{3}{|c|}{$=$ lemah } \\
\hline Skor $3=$ cukup penting & $41 \%$ & & \multicolumn{3}{|c|}{ = cukup } \\
\hline Skor $2=$ tidak penting & $61 \%$ & & \multicolumn{3}{|c|}{$=$ kuat } \\
\hline Skor 1 = sangat tidak penting & $81 \%$ & $0 \%$ & \multicolumn{3}{|c|}{$=$ sangat kuat } \\
\hline
\end{tabular}

Tabel 7. Perhitungan skor dan kriteria interpretasi skor

\begin{tabular}{lll}
\hline Sub program inisiatif & Skor & Kriteria \\
\hline Menambah jenis produk yang ditawarkan & $72 \%$ & Kuat \\
Menciptakan jenis layanan baru yang bernilai tambah & $48 \%$ & Cukup \\
Merancang sistem informasi penjualan & $70 \%$ & Kuat \\
Membuat sistem informasi penjualan & $62 \%$ & Kuat \\
Mengaplikasikan sistem informasi penjualan & $62 \%$ & Kuat \\
Merekayasa ulang proses bisnis perbaikan komputer & $64 \%$ & Kuat \\
Merekayasa ulang proses bisnis penanganan garansi & $66 \%$ & Kuat \\
Merekayasa ulang proses bisnis pengantaran barang & $50 \%$ & Cukup \\
Merekayasa ulang proses bisnis pembayaran & $62 \%$ & Kuat \\
\hline
\end{tabular}

Tabel 8. Prioritas Sub Program Inisiatif

\begin{tabular}{ccl}
\hline Prioritas & Perhitungan Skor & Sub Program Inisiatif \\
\hline 1 & $72 \%$ & Menambah jenis produk yang ditawarkan \\
2 & $70 \%$ & Merancang sistem informasi penjualan \\
3 & $66 \%$ & Merekayasa ulang proses bisnis penanganan garansi \\
4 & $64 \%$ & Merekayasa ulang proses bisnis perbaikan komputer \\
5 & $62 \%$ & Membuat sistem informasi penjualan \\
6 & $62 \%$ & Mengaplikasikan sistem informasi penjualan \\
7 & $62 \%$ & Merekayasa ulang proses bisnis pembayaran \\
8 & $50 \%$ & Merekayasa ulang proses bisnis pengantaran barang \\
9 & $48 \%$ & Menciptakan jenis layanan baru yang bernilai tambah \\
\hline
\end{tabular}

sebesar 0,076, standar deviasi berada pada rentang yang bisa diterima yaitu 0,5 atau lebih kecil.

\section{Prioritas sub program inisiatif}

Berdasarkan hasil perhitungan skor sub program-sub program inisiatif pada Tabel 7 , urutan prioritas sub program inisiatif dapat dilihat pada Tabel 8.

\section{Program inisiatif pengembangan customize product/service}

Rencana aktivitas pelaksanaan program inisiatif menambah jenis produk ditargetkan sepanjang tahun sejak bulan pertama, sedangkan rencana aktivitas pelaksanaan program inisiatif menciptakan layanan baru ditargetkan tiga kali dalam setahun, yakni pada bulan ke-2, ke-6, dan ke-10. Rencana aktivitas selengkapnya dapat dilihat pada Tabel 9.Realisasi jumlah aktivitas 
Tabel 9. Program inisiatif pengembangan customize product/service

\begin{tabular}{lcccccccccccccc}
\hline & $\begin{array}{c}\text { Rencana aktivitas } \\
\text { pelaksanaan program } \\
\text { inisiatif }\end{array}$ & $\begin{array}{c}\text { Target } \\
\text { setahun }\end{array}$ & $\mathbf{1}$ & $\mathbf{2}$ & $\mathbf{3}$ & $\mathbf{4}$ & $\mathbf{5}$ & $\mathbf{6}$ & $\mathbf{7}$ & $\mathbf{8}$ & $\mathbf{9}$ & $\mathbf{1 0}$ & $\mathbf{1 1}$ & $\mathbf{1 2}$ \\
\hline 1 & $\begin{array}{l}\text { Menambah jenis } \\
\text { produk }\end{array}$ & $12 \mathrm{x}$ & $\bullet$ & $\bullet$ & $\bullet$ & $\bullet$ & $\bullet$ & $\bullet$ & $\bullet$ & $\bullet$ & $\bullet$ & $\bullet$ & $\bullet$ & $\bullet$ \\
2 & $3 \mathrm{x}$ & & $\bullet$ & & & & $\bullet$ & & & & $\bullet$ \\
\hline
\end{tabular}

Tabel 10. Key performance indicator program inisiatif pengembangan customize product/service

\begin{tabular}{|c|c|c|c|c|c|c|c|c|c|c|c|c|}
\hline \multirow{2}{*}{\multicolumn{2}{|c|}{$\begin{array}{c}\text { Rencana aktivitas } \\
\text { pelaksanaan program } \\
\text { inisiatif }\end{array}$}} & \multirow[b]{2}{*}{$\begin{array}{c}\text { Target } \\
\text { sampai } \\
\text { bulan ke-2 }\end{array}$} & \multicolumn{10}{|c|}{ Jadwal aktifitas } \\
\hline & & & 1 & 2 & 3 & 4 & 5 & 6 & 7 & 8 & $\begin{array}{l}\text { Realisasi } \\
\text { jumlah } \\
\text { aktivitas }\end{array}$ & $\begin{array}{c}\text { Indikator } \\
\text { kinerja }\end{array}$ \\
\hline \multirow{2}{*}{$\begin{array}{l}1 \\
2\end{array}$} & Menambah jenis produk & $2 \mathrm{x}$ & $\bullet$ & $\bullet$ & & & & & & & 2 & 3 \\
\hline & $\begin{array}{l}\text { Menciptakan layanan } \\
\text { baru }\end{array}$ & $1 \mathrm{x}$ & & $\bullet$ & & & & & & & 1 & 3 \\
\hline
\end{tabular}

3, $00<\mathrm{X} \leq 3,50$, menunjukkan nilai KPI berklasifikasi baik sehingga target perusahaan berpotensi akan tercapai.

Tabel 11. Program inisiatif pemanfaatan teknologi informasi

\begin{tabular}{|c|c|c|c|c|c|c|c|c|c|c|c|c|c|c|}
\hline \multirow{2}{*}{\multicolumn{2}{|c|}{$\begin{array}{c}\text { Rencana aktivitas } \\
\text { pelaksanaan program } \\
\text { inisiatif }\end{array}$}} & \multirow{2}{*}{$\begin{array}{c}\text { Target } \\
\text { setahun }\end{array}$} & \multicolumn{12}{|c|}{ Jadwal aktifitas } \\
\hline & & & 1 & 2 & 3 & 4 & 5 & 6 & 7 & 8 & 9 & 10 & 11 & 12 \\
\hline 1 & $\begin{array}{l}\text { Merancang } \\
\text { sistem informasi } \\
\text { penjualan }\end{array}$ & $1 x$ & $\bullet$ & & & & & & & & & & & \\
\hline 2 & $\begin{array}{l}\text { Membuat } \\
\text { sistem informasi } \\
\text { penjualan }\end{array}$ & $1 \mathrm{x}$ & $\bullet$ & & & & & & & & & & & \\
\hline 3 & $\begin{array}{l}\text { Mengaplikasikan } \\
\text { sistem informasi } \\
\text { penjualan }\end{array}$ & $12 x$ & $\bullet$ & $\bullet$ & $\bullet$ & $\bullet$ & • & $\bullet$ & $\bullet$ & $\bullet$ & $\bullet$ & $\bullet$ & $\bullet$ & $\bullet$ \\
\hline
\end{tabular}

menambah jenis produk sama dengan target sampai bulan ke-2, demikian pula realisasi jumlah aktivitas menciptakan layanan baru sama dengan target sampai bulan ke-2. Klasifikasi hasil monitoring dan evaluasi sampai bulan ke-2, dapat dilihat pada Tabel 10 .

Hasil monitoring menunjukkan nilai KPI berklasifikasi baik sehingga target perusahaan berpotensi akan tercapai.

\section{Program inisiatif pemanfaatan teknologi informasi}

Rencana aktivitas pelaksanaan program inisiatif merancang sistem informasi penjualan ditargetkan pada bulan ke-1, rencana aktivitas pelaksanaan program inisiatif membuat sistem informasi penjualan ditargetkan pada bulan ke-1, dan rencana aktivitas pelaksanaan program inisiatif mengaplikasikan sistem informasi penjualan ditargetkan sepanjang tahun sejak bulan ke-1. Rencana aktivitas ini dapat dilihat pada Tabel 11.

Realisasi jumlah aktivitas merancang sistem informasi penjualan sama dengan target sampai bulan ke-1, realisasi aktivitas membuat sistem informasi penjualan sama dengan target sampai bulan ke-1, dan aktivitas mengaplikasikan sistem informasi penjualan juga sudah dimulai pada bulan ke-1. Klasifikasi hasil monitoring dan evaluasi sampai bulan ke-1, dapat dilihat pada Tabel 12. 
Tabel 12. Key performance indicator program inisiatif pemanfaatan teknologi informasi

\begin{tabular}{|c|c|c|c|c|c|c|c|c|c|c|c|}
\hline & \multirow[b]{2}{*}{$\begin{array}{c}\text { Rencana aktivitas } \\
\text { pelaksanaan program } \\
\text { inisiatif }\end{array}$} & \multirow[b]{2}{*}{$\begin{array}{c}\text { Target } \\
\text { sampai } \\
\text { bulan ke-1 }\end{array}$} & \multicolumn{9}{|c|}{ Jadwal aktifitas } \\
\hline & & & 12 & 3 & 4 & 5 & 6 & 7 & 8 & $\begin{array}{c}\text { Realisasi } \\
\text { jumlah } \\
\text { aktivitas }\end{array}$ & $\begin{array}{c}\text { Indikator } \\
\text { kinerja }\end{array}$ \\
\hline 1 & $\begin{array}{l}\text { Merancang sistem } \\
\text { informasi penjualan }\end{array}$ & $1 \mathrm{x}$ & $\bullet$ & & & & & & & 1 & 3 \\
\hline 2 & $\begin{array}{l}\text { Membuat sistem } \\
\text { informasi penjualan }\end{array}$ & $1 \mathrm{x}$ & $\bullet$ & & & & & & & 1 & 3 \\
\hline 3 & $\begin{array}{l}\text { Mengaplikasi sistem } \\
\text { informasi penjualan }\end{array}$ & $1 \mathrm{x}$ & $\bullet$ & & & & & & & 1 & 3 \\
\hline
\end{tabular}

3, $00<\mathrm{X} \leq 3,49$ : Menunjukkan nilai KPI berklasifikasi baik sehingga target perusahaan berpotensi akan tercapai.

Tabel 13. Program inisiatif pengembangan proses bisnis yang responsif dan efisien

\begin{tabular}{|c|c|c|c|c|c|c|c|c|c|c|c|c|c|}
\hline & \multirow{2}{*}{$\begin{array}{c}\text { Rencana aktivitas } \\
\text { pelaksanaan program inisiatif }\end{array}$} & \multirow{2}{*}{$\begin{array}{c}\text { Target } \\
\text { setahun }\end{array}$} & \multicolumn{11}{|c|}{ Jadwal aktifitas } \\
\hline & & & 1 & 2 & 3 & 4 & 56 & 7 & 8 & 9 & 10 & 11 & 12 \\
\hline 1 & $\begin{array}{l}\text { Rekayasa ulang proses bisnis perbaikan } \\
\text { komputer }\end{array}$ & $1 \mathrm{x}$ & • & & & & & & & & & & \\
\hline 2 & $\begin{array}{l}\text { Rekayasa ulang proses bisnis } \\
\text { penanganan garansi }\end{array}$ & $1 \mathrm{x}$ & $\bullet$ & & & & & & & & & & \\
\hline 3 & $\begin{array}{l}\text { Rekayasa ulang proses bisnis } \\
\text { pengantaran order }\end{array}$ & $1 \mathrm{x}$ & $\bullet$ & & & & & & & & & & \\
\hline 4 & $\begin{array}{l}\text { Rekayasa ulang proses bisnis } \\
\text { pembayaran }\end{array}$ & $1 x$ & $\bullet$ & & & & & & & & & & \\
\hline
\end{tabular}

Tabel 14. Key performance indicator program inisiatif pengembangan proses bisnis

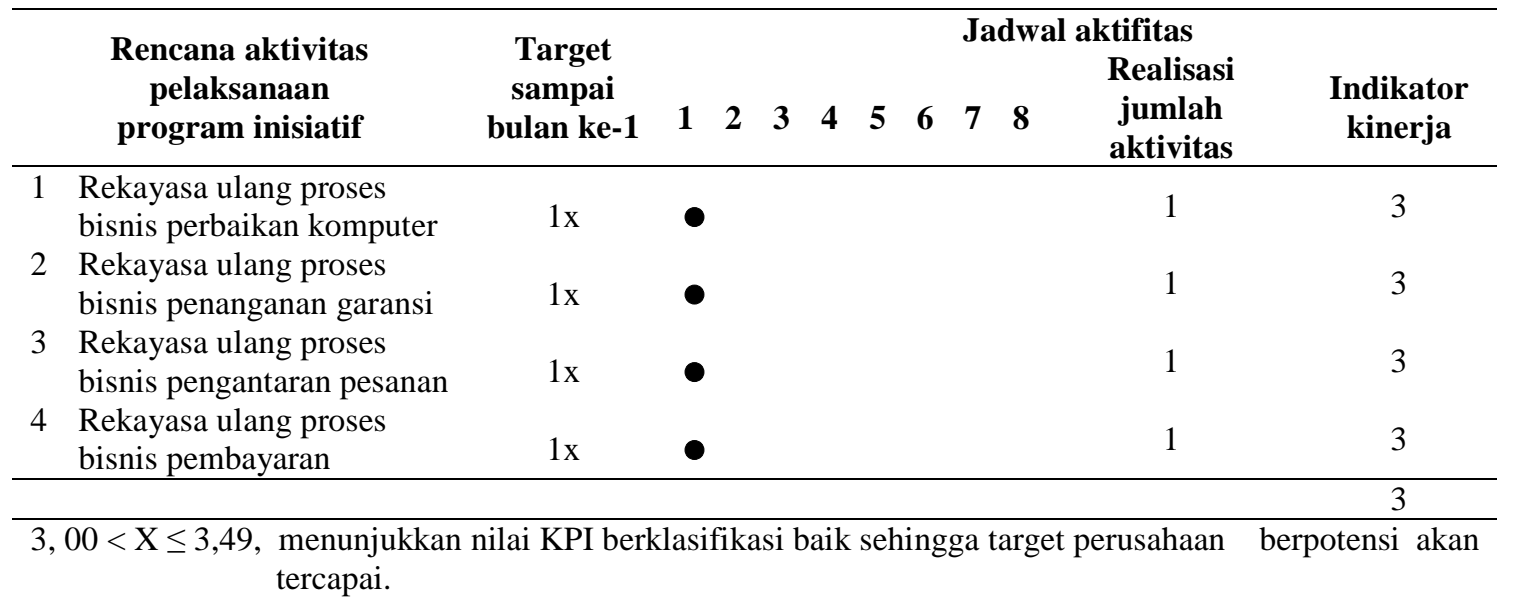

Hasil monitoring menunjukkan nilai KPI berklasifikasi baik sehingga target perusahaan berpotensi akan tercapai.

\section{Program Inisiatif Pengembangan Proses Bisnis yang Responsif dan Efisien}

Rencana aktivitas pelaksanaan program inisiatif rekayasa ulang proses bisnis perbaikan komputer, rekayasa ulang proses bisnis penanganan garansi, rekayasa ulang proses bisnis pengantaran order, dan rekayasa ulang proses bisnis pembayaran semuanya ditargetkan pada bulan ke-1. Rencana aktivitas ini dapat dilihat pada Tabel 13.

Realisasi jumlah aktivitas rekayasa ulang proses bisnis perbaikan komputer, rekayasa ulang proses bisnis penanganan garansi, rekayasa ulang proses bisnis pengantaran pesanan, dan rekayasa 
ulang proses bisnis pembayaran sama dengan target sampai bulan ke-1. Klasifikasi hasil monitoring dan evaluasi sampai bulan ke-1, dapat dilihat pada Tabel 14.

Hasil monitoring menunjukkan nilai KPI berklasifikasi baik sehingga target perusahaan berpotensi akan tercapai.

\section{SIMPULAN}

Hasil penelitian menunjukkan bahwa berdasarkan monitoring dan evaluasi programprogram inisiatif nilai key performance indicator berklasifikasi baik, sehingga target perusahaan berpotensi akan tercapai.

\section{DAFTAR PUSTAKA}

Davenport, T.H.; Short, J.E. (1990). The New Industrial Engineering; Information Technology and Business Process Design. MIT Sloan Management Review, Summer 1990, July 1990, pp. 11 - 27.

Kaplan, R.S. (2006). Target Setting, Balanced Scorecard Report. Harvard Business School Publishing.

Johansshon, HJ.; McHugh, P.; Pendlebury, A.J.; Wheeler III, W.A. (1995). Rekayasa Ulang Proses Bisnis Strategi Terobosan untuk Dominasi Pasar. Jakarta: Binarupa Aksara.

Peppard, J.; Rowland, P. (1995). The Essence of Business Process Reengineering. London, UK: Prentice Hall International Ltd.

Qurtubi. (2013). Integrasi Balanced Scorecard dan Process Based Framework untuk Rekayasa Ulang Proses Bisnis. Tesis Magister Teknik Industri Universitas Islam Indonesia.

Thaib, M. (2012). Business Architecture for Competitive Strategic Planning. Alomet \& Friends.

Yuwono, S.; Sukarno, E.; Ichsan, M. (2003). Petunjuk Praktis Penyusunan Balance Scorecard, Menuju Organisasi yang Berfokus pada Strategi. Jakarta: Gramedia. 